\title{
A NOVEL INTERVENTION PROGRAM (CRICFIT) FOR THE STRENGTH AND CONDITIONING OF ADOLESCENT CRICKET PLAYERS
}

original paper

() University School of Physical Education in Wrocław

DOI: https://doi.org/10.5114/hm.2018.73610

\section{LEE POTE, CANDICE CHRISTIE}

Department of Human Kinetics and Ergonomics, Rhodes University, Grahamstown, South Africa

\begin{abstract}
Purpose. The purpose of the current investigation was to examine the effects of a 4-week field-based intervention program (CricFit) on general fitness, with the program designed to reflect the demands of the game in an adolescent population.

Methods. The total of 28 schoolboy cricketers (aged 15-19 years) were assigned to either a control $(n=14)$ or experimental $(n=14)$ group. Both groups performed traditional net and field-based training over a 4 -week period (one net- and one field-based session), with the experimental group executing 2 additional 35-45-minute conditioning sessions per week. Prior to and post the 4 -week period, measures were recorded with a test battery that was specific to the movement demands associated with intermittent sports.
\end{abstract}

Results. Both groups showed significant $(p<0.05)$ improvements in most responses, but the changes for the experimental group were greater than those shown in the control group, likely owing to the additional conditioning sessions. Furthermore, significant $(p<0.05)$ changes were observed between the two groups for the percentage body fat, flexibility, plank time, 20-m sprint time, push ups, and 25-m shuttle distance.

Conclusions. It was concluded that the CricFit intervention program can be used by coaches and conditioning specialists to improve cricket-specific fitness throughout the pre-season period.

Key words: fitness, high school students, physical training

\section{Introduction}

The game of cricket is played in over 100 countries worldwide and is constantly growing in popularity [1]. The first form of the game, the 5-day test match, has evolved into a 1-day game and more recently into the 20-over format [1,2] and the game is a lot more physically demanding than it used to be [3]. Furthermore, with the introduction of different match formats, players are subjected to longer seasons and increased workloads. This means that they need to remain physically fit for extended time periods, specifically to reduce injury risk [4-6].

The increase in injury risk is of particular concern at younger levels as research has shown that adolescent cricket injury risk is higher than that in adult cricketers [7]. The seasonal incidence of injury among schoolboy and club cricketers in South Africa between the age of 19 and 24 years equals $34.2-49 \%$, with the main injuries occurring in the lower back and hamstrings for bowlers and batsmen, respectively [7-9]. This is of particular concern, especially since the return-to-play time for most injuries is approximately 21 days in this age group [7, 8].

While a number of conditioning programs have been developed, most are used by specialists in highperformance settings $[1,10]$. There is therefore a disparity between programs implemented at the elite versus at the amateur level. To date, only one research paper has looked at the strength and conditioning practices of amateur level cricket coaches and strength and conditioning specialists [6]. The research has found that there is a distinct lack of strength and conditioning programs for adolescent cricket players. Furthermore, workloads are not normally monitored and seasons of different sporting codes overlap, resulting

Correspondence address: Lee Pote, Department of Human Kinetics and Ergonomics, Rhodes University, P.O. Box 94,

Grahamstown, 6140, South Africa, e-mail: g06p1630@campus.ru.ac.za

Received: September 7, 2017

Acepted for publication: November 11, 2017

Citation: Pote L, Christie C. A novel intervention program (CricFit) for the strength and conditioning of adolescent cricket players. Hum Mov. 2018;19(1):34-43; doi: https://doi.org/10.5114/hm.2018.73610. 
in school children playing multiple sports at a time. This is problematic in terms of the time period that pupils are exposed to their pre-season training block, which typically lasts 4 weeks. Furthermore, it is not known whether players at a school or club level are being under-, over-, or optimally trained. Most coaches indicated a lack of knowledge and time as factors affecting their ability to prevent injury and ensure that players are adequately conditioned. A low-cost or nocost intervention program that is easily implementable at all schools and clubs, regardless of resources, funding, and qualifications, would therefore be ideal [6] and would go a long way to improve physical fitness [11]. Furthermore, physical attributes that players develop through training and competition help with their success as a cricketer [12]. To the authors' knowledge, no targeted and easily implementable strength and conditioning program has been established that could be administered by coaches with little to no strength and conditioning experience. It is thus important to expand the understanding of strength and conditioning practices at an adolescent level, not only to improve physical fitness, but also to reduce the risk of injury.

Therefore, the purpose of this study was to examine the effects of a 4-week pre-season field-based intervention (CricFit) on general fitness measures, designed to reflect the demands of a game in an adolescent population. The program was implemented in addition to the traditional net and field-based training. It was hypothesized that the intervention would significantly improve physical fitness parameters and would be an ideal adjunct to traditional net practices.

\section{Material and methods}

\section{Participants}

The total of 28 schoolboy cricket players (characteristics shown in Table 2) were recruited for the study from the Kingswood College Senior School in Grahamstown, Eastern Cape, South Africa. All participants played for the top school team in their specific age groups. Ethical clearance was granted by the Department of Human Kinetics and Ergonomics Ethical Standards Committee for research involving human participants (Rhodes University, Grahamstown, South Africa), and all players were informed of the benefits and risks of the investigation. Prior to performing any testing or intervention sessions, the players completed a physical activity screening questionnaire to ensure that they were healthy and free of injury. The individuals were then assigned either to the control $(n=14)$ or to the experimental group $(n=14)$. The players were matched according to baseline test and fitness levels, which helped guarantee that changes were not a result of between-day reliability differences. There were no significant differences between the groups besides those with regard to age and percent body fat (the control group were younger and had less percent body fat) and all participants played for their respective first teams. Thus, the results must be seen within the context of this limitation. The participants had also just returned from a 1-month holiday where no exercise was prescribed or completed (this was prior to the intervention; the completion of the first test battery) and thus represented a similar level of fitness (the participants had been told to refrain from training during the holidays). Furthermore, all players were boarding scholars at the same school and thus were exposed to the same conditions and nutrition.

\section{Study design}

The current investigation study was a pre-, posttest design which included an experimental and control group. The experimental group participated in a strength and conditioning intervention while the control group did not. The intervention took place over a 4-week pre-season period, prior to the first fixture being played, and was designed on the basis of previous literature on strength and conditioning practices for intermittent sports, as well as the movement demands of cricket [6,13-17]. The players in the experimental group were required to complete 2 sessions per week, each of 35-45 minutes, depending on the stage of intervention. The control group only participated in traditional net and field-based training. The fact that specialised equipment is not always available at the schoolboy level (e.g. gym equipment) means that the intervention was designed to incorporate the minimal amount of apparatus necessary and focused more on body weight exercises. Thus, only a medicine ball, thera-bands, and agility ladders were needed for training. Adherence to the program was controlled through a roll call at each session and participants were excluded if more than 2 sessions were missed.

The purpose of the CricFit intervention was to improve the general physical fitness of cricket players. The intervention consisted of a number of exercises that centred on the movement demands associated with the sport of cricket, as well as injury prevention exercises (specifically Nordic lowers and core work) (Table 1). Thus the program focused on aspects such as agility, strength, power, endurance, speed, flexibility, 


\section{HUMAN MOVEMENT}

L. Pote, C. Christie, Cricket strength and conditioning

Table 1. Weeks 1-4 of the CricFit intervention program

\begin{tabular}{|c|c|c|c|c|c|}
\hline \multicolumn{3}{|l|}{ WEEK 1} & \multicolumn{3}{|l|}{ WEEK 2} \\
\hline \multicolumn{3}{|l|}{ Session 1} & \multicolumn{3}{|l|}{ Session 1} \\
\hline & Sets & Reps & & Sets & Reps \\
\hline Sprints $(20 \mathrm{~m})$ & 2 & 6 & Sprints $(20 \mathrm{~m})$ & 2 & 6 \\
\hline Plank & 2 & $45 \mathrm{~s}$ & Plank & 3 & $45 \mathrm{~s}$ \\
\hline Ladder drills* & 1 & 3 & Ladder drills* & 1 & 3 \\
\hline Skipping & 2 & $1 \mathrm{~min}$ & Skipping & 3 & $1 \mathrm{~min}$ \\
\hline Lizard crawls & 2 & 10 & Lizard crawls & 3 & 10 \\
\hline Nordic lowers & 2 & 5 & Nordic lowers & 2 & 6 \\
\hline \multicolumn{3}{|l|}{ Session 2} & \multicolumn{3}{|l|}{ Session 2} \\
\hline 25-m shuttle & 2 & $2^{\#}$ & 25-m shuttle & 3 & $2^{\#}$ \\
\hline Side plank & 2 & $45 \mathrm{~s}$ & Side plank & 2 & $45 \mathrm{~s}$ \\
\hline W-sprint agility drill & 2 & $1 \mathrm{~min}$ & W-sprint agility drill & 3 & $1 \mathrm{~min}$ \\
\hline Overhead med ball slams & 2 & $45 \mathrm{~s}$ & Overhead med ball slams & 3 & $45 \mathrm{~s}$ \\
\hline \multirow[t]{2}{*}{ Burpees } & 2 & $45 \mathrm{~s}$ & Burpees & 3 & $45 \mathrm{~s}$ \\
\hline & & & Nordic lowers & 2 & 6 \\
\hline \multicolumn{3}{|l|}{ WEEK 3} & \multicolumn{3}{|l|}{ WEEK 4} \\
\hline \multicolumn{3}{|l|}{ Session 1} & \multicolumn{3}{|l|}{ Session 1} \\
\hline & Sets & Reps & & Sets & Reps \\
\hline Sprints & 2 & 8 & Sprints & 2 & 8 \\
\hline Plank & 2 & $1 \mathrm{~min}$ & Plank & 3 & $1 \mathrm{~min}$ \\
\hline Ladder drills* & 2 & 3 & Ladder drills* & 2 & 3 \\
\hline Squat jumps & 2 & $45 \mathrm{~s}$ & Squat jumps & 3 & $45 \mathrm{~s}$ \\
\hline Lizard crawls & 3 & 12 & Lizard crawls (thera-bands) & 3 & 12 \\
\hline Nordic lowers & 3 & 6 & Nordic lowers & 3 & 8 \\
\hline \multicolumn{3}{|l|}{ Session 2} & \multicolumn{3}{|l|}{ Session 2} \\
\hline 25-m shuttle & 3 & $2^{\#}$ & 25-m shuttle & 4 & $2^{\#}$ \\
\hline Side plank & 3 & $45 \mathrm{~s}$ & Side plank & 3 & $1 \mathrm{~min}$ \\
\hline W-sprint agility drill & 3 & $1 \mathrm{~min}$ & W-sprint agility drill & 3 & $1 \mathrm{~min}$ \\
\hline Overhead med ball slams & 2 & $1 \mathrm{~min}$ & Overhead med ball slams & 3 & $1 \mathrm{~min}$ \\
\hline Burpees & 2 & $1 \mathrm{~min}$ & Burpees & 3 & $1 \mathrm{~min}$ \\
\hline Nordic lowers & 3 & 6 & Nordic lowers & 3 & 8 \\
\hline
\end{tabular}

* each set consisted of single runs, in-and-outs, double runs, and shuffles

\# 1 repetition $=1 \times 25-\mathrm{m}$ shuttle run (maximum effort)

repeat sprint ability, and injury prevention. These prevention exercises targeted specifically the lower back and hamstring musculature, which are the most commonly injured areas in bowlers and batsmen, respectively [4]. Exercises throughout the intervention were varied to avoid repetition and monotony.

Lastly, the intervention also incorporated a dynamic warm-up and a static cool-down (ca. 5 minutes each). Both the warm-up and cool-down focused specifically on the lower limb and back musculature.

Quality of movement is important for ladder drills, and intensity and running form is essential when sprint- ing. Breaks between sets, $30 \mathrm{~s}$; breaks between exercises, $1 \mathrm{~min}$; ladder length, $4 \mathrm{~m}$.

\section{Procedures}

The control and experimental group were required to perform a battery of physical tests prior to and after completing a 4-week cricket-specific intervention program (the control group did not perform the intervention program). One habituation and 2 testing sessions were required for the study. All sessions were carried out at the High Performance Centre at King- 
swood College, Grahamstown, South Africa and all testing took place at the end of the winter break, in order to ensure similar baseline measures of fitness.

During the habituation session, the intervention was explained to the players both verbally and in writing. The objectives of the research project were also clarified, information was provided regarding the test protocol and intervention procedures. After this, basic anthropometric and demographic data were collected for each player, which included age, stature, mass, and sum of 7 skinfolds (chest, triceps, subscapular, axilla, abdominal, suprailiac, and thigh). The players were also instructed not to consume alcohol 24 hours prior to testing, not to perform any strenuous exercise before testing, and to eat a light meal at least an hour before. Lastly, the players from both groups were asked to refrain from any additional exercise during the intervention period (this was monitored by the researcher). Thus, players from both groups performed one net and one middle session (a session that mimics a match scenario) per week, but those in the experimental group completed 2 additional conditioning sessions on alternate days. The duration of the net and middle sessions were approximately 2 hours each.

Testing session 1 required the players to complete the test battery prior to performing the intervention. The tests were performed in the order presented below.

\section{Sit and reach flexibility}

This occurred before the player was warmed up. The players were required to only stretch until the muscle was tight and not until any pain was felt. A sit and reach box was provided and the 'zero' point on the box was set to $260 \mathrm{~mm}$. When performing the test, the player sat on the floor with their knees extended, ankles flexed, and bare feet against the edge of the box. The participant then flexed at the hip and reached towards their toes with both hands, making sure that the knees were not flexed at any point during the test.

\section{Lower limb power}

The player stood with their feet comfortably apart, behind a demarcated line. The player was allowed to bend (flex) the knees and swing the arms prior to the jump; however, a run-up or a shuffle step prior to the jump was not allowed. The participant was allowed a maximum of 2 efforts. The maximum distance $(\mathrm{cm})$ from the take-off line to the back of the heel closest to the take-off line was recorded.

\section{Upper body power}

The test involved throwing a 3-kg medicine ball forward over the head for a maximum distance. The player stood with feet shoulder width apart and behind the start line and faced the direction in which they intended to throw. The ball was then drawn backwards over the head (elbow bend was permitted) and the trunk was permitted to extend back as the arms were taken behind the head. In one motion, the ball was then thrown forward for a maximum distance. Several practices were required to get the best trajectory for a maximum distance. The player's feet were allowed to lift off the floor during the throw; however, the participant was not allowed to step or fall forward over the line after the ball was released. Three trials were allowed.

\section{Agility}

The players' speed and agility were assessed with the Illinois agility test. Each player started off in the prone position (lying down) with their chin touching the start line. When the whistle was blown, the player completed the course in their quickest time possible. Times were recorded with a stopwatch. The participants completed 2 tests each, separated by a recovery period.

\section{Speed}

The players' speed was measured in a 20-m sprint. The test determined their maximum sprint speed, as well as their ability to accelerate from a stationary position. Each player was required to produce an allout effort, therefore a thorough warm-up consisting of sub-maximal running and stretching was performed prior to testing. A stopwatch was used to time each participant, and 2 maximal efforts were completed separated by a 1-minute recovery period.

\section{Muscle endurance}

For muscle endurance, the players performed the maximum amount of push-ups possible in 1 minute. Each player started with their thumbs $0-5 \mathrm{~cm}$ wider than their shoulder width and the repetition was only counted if their back and body were straight, they touched the tester's fist when descending and finished with their arms fully extended (straight). 


\section{Core strength}

This assessment determined the maximum amount of time that an elevated plank position could be held by a player. The upper body of the participant was supported off the ground by the elbows, forearms, and toes, with the legs and torso held straight. The stopwatch was started once the player was in this position and the test ended when the player was unable to maintain this posture.

\section{Repeat sprint ability}

Repeat sprint ability was assessed with the use of a 25-m shuttle test. Six cones were set at 5-m intervals. At the start of the test, each player was required to sprint to cone 1 , touch the base of the cone with their hand, and then sprint back to the starting position, where they touched the base of the cone with their hand and sprinted to cone 2 . This process was repeated until all the cones were touched. After $30 \mathrm{~s}$, a whistle was blown and the distance that the player covered was measured. The participant was then given a 35-s break, after which the process was repeated again. This occurred 6 times and each time the $30 \mathrm{~s}$ were completed, the distance was recorded.

Prior to completing the test battery, the players performed a dynamic warm-up and after testing, a static stretching cool-down was accomplished. This testing session also took place at least 3 days prior to the start of the intervention so as for the players to be fully recovered.

Testing session 2 occurred after the intervention was completed. The participants performed the same test battery as in session 1 to determine whether there were any improvements. The tests were carried out in the same order, as well as at the same time of the day.

\section{Statistical analyses}

Statistics software (StatSoft, Inc., 2011, STATISTICA $^{\circ}$, version 13.0) was used to perform all statistical analyses. Descriptive statistics were calculated for all dependent variables (mean $\pm S D$ ). A t-test for dependent samples was applied to calculate any significance within each group pre and post. A t-test for independent samples (using the change in absolute values) served to determine the significance comparing the control and experimental groups. A mixed model ANOVA (general linear model) was used to analyse the interaction effect between the protocol and time, as well as to adjust the data through post-hoc analysis.
The probability level of $p<0.05$ denoted statistical significance for all tests. The effect size $(E S)$ calculation (Cohen's $d$ ) characterized the magnitude of difference within and between groups [18]. The criteria for interpreting $E S$ were: $<0.2$ : trivial, from 0.2 to $<0.5$ : small, from 0.5 to $<0.8$ : medium, $\geqslant 0.8$ : large.

\section{Ethical approval}

The research related to human use has been complied with all the relevant national regulations and institutional policies, has followed the tenets of the Declaration of Helsinki, and has been approved by the authors' institutional review board or an equivalent committee.

\section{Informed consent}

Informed consent has been obtained from all individuals included in this study.

\section{Results}

A significant difference $(p<0.05)$ was shown for age between groups, with the experimental group being 2 years older than the control group. The groups were matched for all other variables pre-intervention (Table 2). A significant decrease $(p<0.05)$ was observed for both the sum of 7 skinfolds $(E S=0.68)$ and body fat percentage $(E S=0.66)$ measures within the experimental group only post-intervention (Table 2). The largest decrease occurred at the suprailiac skinfold site. Furthermore, significant decreases $(p<0.05)$ were noted between the control and experimental groups for the sum of 7 skinfolds $(E S=1.43)$ and percentage body fat $(E S=1.42)$ post-intervention (overall absolute change).

\section{Sit and reach flexibility}

For flexibility, a significant increase $(p<0.05 ; E S=$ 0.46 and 0.88 ) was observed within the experimental group, as well as the absolute change between the two groups (Table 3). ES for the control group was trivial $(E S=0.04)$. An interaction effect was also observed between conditions over time $(p=0.03)$. The mean percentage change was $27.42 \%$ and $7.01 \%$ for the control and experimental groups, respectively.

\section{Standing broad jump}

No significant differences were observed within or between the groups for the standing broad jump measure (Table 3), despite a large increase within the experimental group $(E S=0.81)$. The percentage 
Table 2. Basic demographic, morphological, and anthropometric characteristics of the control and experimental groups (mean $\pm S D$ )

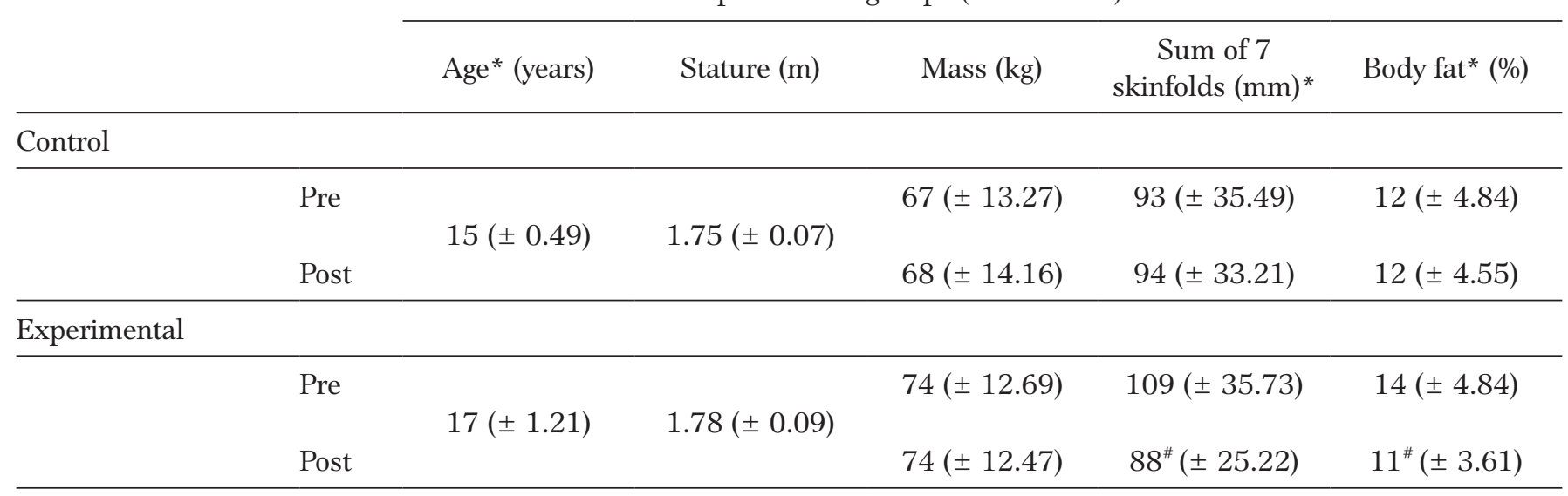

* significant difference between the control and experimental groups (overall absolute change)

\# significant difference within groups $(p<0.05)$

change was $2.70 \%$ for the control group $(E S=0.35)$ and $3.58 \%$ for the experimental group. No interaction effect was noted $(p=0.72)$.

\section{Overhead medicine ball throw $(3 \mathrm{~kg})$}

No significant changes were observed for the medicine ball throw, both within and between groups (Table 3). There was, however, a meaningful increase in the experimental and control group $(E S=0.75$ and 1.19 , respectively), with a percentage change of $1.05 \%$ and $4.25 \%$ for the control and experimental groups. No interaction effect was detected $(p=0.08)$.

\section{Agility}

A significant decrease $(p<0.05)$ was observed within the control $(E S=1.76)$ and experimental $(E S=$ 3.95) groups for agility. There was no difference between the groups (Table 3), although a mean percentage change of $8.57 \%$ and $10.31 \%$ was shown for the control and experimental groups, respectively. No interaction effect was noted ( $p=0.28)$.

\section{0-m sprint}

There were significant decreases $(p<0.05)$ in the $20-\mathrm{m}$ sprint time for both the control $(E S=1.34)$ and experimental $(E S=5.55)$ groups. A significant decrease $(p<0.05 ; E S=4.30)$ was also observed overall (absolute change) between the two groups (Table 3). An interaction effect was shown between conditions over time ( $p=0.001)$. Overall mean percentage change equalled $8.41 \%$ for the control group and $26.78 \%$ for the experimental group.

\section{Push-ups}

A significant increase $(p<0.05 ; E S=0.90)$ in pushups was shown within the experimental group over time (improvement). An overall significant difference ( $p<0.05$; $E S=1.04$ ) was also observed between the control (percentage change, 4.35\%) and experimental (percentage change, 24.84\%) groups for the number of push-ups completed (Table 3). There was an interaction effect between conditions over time $(p=0.02)$.

\section{Plank}

There was a significant increase $(p<0.05$; ES $=$ 1.45) in plank time in the experimental group (Table 3). A significant increase $(p<0.05 ; E S=1.97)$ was also shown for the overall absolute change between the two groups (percentage change, $1.88 \%$ for the control group and $91.86 \%$ for the experimental group). An $E S$ of 0.13 was determined in the control group. Furthermore, an interaction effect was observed over time between conditions $(p=0.001)$.

\section{5-m shuttle run}

For the 25-m shuttle run, significant increases $(p<$ $0.05)$ were observed in both the control $(E S=1.08$; percentage change, $6.12 \%)$ and experimental $(E S=4.38$; percentage change, $13.58 \%$ ) groups. Moreover, a significant increase $(p<0.05 ; E S=1.61)$ was also proved between the two groups overall (Table 3). An interaction effect was observed over time between the 2 conditions $(p=0.001)$. 
Table 3. Pre- and post-intervention responses for the control and experimental groups (mean $\pm S D$ )

\begin{tabular}{|c|c|c|c|c|c|c|c|}
\hline $\begin{array}{l}\text { Sit and reach } \\
\text { flexibility* } \\
(\mathrm{mm})\end{array}$ & $\begin{array}{l}\text { Standing } \\
\text { broad jump } \\
\text { (m) }\end{array}$ & $\begin{array}{l}\text { Agility } \\
\text { (s) }\end{array}$ & $\begin{array}{c}\text { Plank time* } \\
\text { (s) }\end{array}$ & $\begin{array}{c}20-\mathrm{m} \\
\text { sprint time* } \\
\text { (s) }\end{array}$ & $\begin{array}{l}\text { Medicine } \\
\text { ball throw } \\
\text { (m) }\end{array}$ & $\begin{array}{c}\text { Push-ups* } \\
\text { (n) }\end{array}$ & $\begin{array}{c}\text { 25-m shuttle } \\
\text { distance* } \\
\text { (m) }\end{array}$ \\
\hline
\end{tabular}

Control

\begin{tabular}{|c|c|c|c|c|c|c|c|c|}
\hline Pre & $\begin{array}{c}44.43 \\
( \pm 98.17)\end{array}$ & $\begin{array}{c}2.19 \\
( \pm 0.26)\end{array}$ & $\begin{array}{c}17.34 \\
( \pm 0.90)\end{array}$ & $\begin{array}{c}101.83 \\
( \pm 20.48)\end{array}$ & $\begin{array}{c}3.52 \\
( \pm 0.19)\end{array}$ & $\begin{array}{c}6.77 \\
( \pm 1.29)\end{array}$ & $\begin{array}{c}32.42 \\
( \pm 10.00)\end{array}$ & $\begin{array}{c}654.00 \\
( \pm 26.21)\end{array}$ \\
\hline Post & $\begin{array}{c}40.79 \\
( \pm 94.58)\end{array}$ & $\begin{array}{c}2.27 \\
( \pm 0.20)\end{array}$ & $\begin{array}{c}15.93^{\&} \\
( \pm 0.69)\end{array}$ & $\begin{array}{c}105.36 \\
( \pm 31.18)\end{array}$ & $\begin{array}{c}3.27^{\&} \\
( \pm 0.18)\end{array}$ & $\begin{array}{c}6.53 \\
( \pm 1.07)\end{array}$ & $\begin{array}{c}33.86 \\
( \pm 10.20)\end{array}$ & $\begin{array}{c}699.18^{\&} \\
( \pm 46.60)\end{array}$ \\
\hline \multicolumn{9}{|l|}{ Experimental } \\
\hline Pre & $\begin{array}{c}45.40 \\
( \pm 87.59)\end{array}$ & $\begin{array}{c}2.20 \\
( \pm 0.14)\end{array}$ & $\begin{array}{c}16.92 \\
( \pm 0.52)\end{array}$ & $\begin{array}{c}110.07 \\
( \pm 58.73)\end{array}$ & $\begin{array}{c}3.65 \\
( \pm 0.17)\end{array}$ & $\begin{array}{c}7.40 \\
( \pm 1.61)\end{array}$ & $\begin{array}{c}32.62 \\
( \pm 8.60)\end{array}$ & $\begin{array}{c}654.67 \\
( \pm 36.21)\end{array}$ \\
\hline Post & $\begin{array}{c}80.50^{\#} \\
( \pm 61.94)\end{array}$ & $\begin{array}{c}2.30 \\
( \pm 0.11)\end{array}$ & $\begin{array}{c}14.93^{\#} \\
( \pm 0.49)\end{array}$ & $\begin{array}{c}185.29^{\#} \\
( \pm 44.29)\end{array}$ & $\begin{array}{c}2.84^{\#} \\
( \pm 0.12)\end{array}$ & $\begin{array}{c}7.85 \\
( \pm 1.76)\end{array}$ & $\begin{array}{c}40.83^{\#} \\
( \pm 9.54)\end{array}$ & $\begin{array}{c}746.79^{\#} \\
( \pm 21.72)\end{array}$ \\
\hline
\end{tabular}

* significant difference between the control and experimental groups (overall absolute change)

\# significant difference within the experimental group

\& significant difference within the control group $(p<0.05)$

\section{Discussion}

The most important finding of the investigation was that the CricFit intervention program had a positive impact on most of the experimental test scores post-intervention. Significant improvements were observed for agility, sprint time, and repeat sprint ability scores post-intervention for the control group, showing that traditional net and field-based coaching techniques also have an impact on certain fitness parameters. However, the changes detected in the intervention group were greater than those seen in the control group (for most measures), thus showing that there were greater benefits with 2 extra strength and conditioning sessions per week (the extra sessions were justifiable) as compared with performing traditional training.

Agility and sprint times decreased significantly $(p<0.05)$ in both groups over the intervention period (greater decreases were shown in the intervention group), which is a similar observation to what has been shown in other intermittent sports interventions [15]. This is an important finding to consider, particularly for the design of late stage rehabilitation programs, as well as pre-season training in the development plan of both adolescents and adults [15]. Furthermore, increased speed and agility are a desirable trait in cricket as all cricketing activities (batting, bowling, and fielding) can benefit from an improvement in these two aspects. For example, batsmen can sprint and turn quicker between the wickets when running and fielders may reduce the amount of runs that the opposition score by moving quickly to the ball. This increase in speed and agility could be attributed to an improvement in the athletes' lower limb power, as shown in other cricketrelated studies [19]. Although the current study showed no significance for standing broad jump (lower limb power), a large $E S(0.81)$ was seen, which may explain the improvements in sprint and agility times. What is more, lower limb power measurements, such as the countermovement jump and the standing broad jump, have been shown to best reflect the speed and change of direction demands of cricket players [19].

The number of push-ups in the experimental group increased significantly $(p<0.05)$ over the 4 -week period. This is imperative for batsmen, bowlers, and fielders. Although push-ups over time are typically a measure of muscle endurance, upper body strength may also improve. In terms of batting, upper body strength has been associated with an increased hitting distance [20]. Thus, the greater the force generated by the muscles in the upper body region during the bat swing, the greater the power output of the cricket stroke [20]. This becomes particularly important on larger cricket grounds, where more force is required of the batsman to clear the boundary. Upper body strength is also key for bowlers and fielders; positive correlations have been shown between the ball release speed and maximum upper body strength, which may increase the speed at which a ball is bowled or thrown [10]. Additionally, although no significant differences were detected for overhead medicine ball throw responses, a large $E S$ was observed between groups post-intervention $(E S=$ 
0.75). This type of training has also been proved to help with injury prevention for throwing when fielding and for fast bowling [10].

The maximum plank time increased significantly $(p<0.05)$ in the experimental group. The finding is similar to the one obtained in another study, where core strength training significantly impacted on muscle and back strength in cricketers [21]. Furthermore, equipment free, core conditioning routines have been shown to raise trunk and core muscle endurance in adolescents [22]. This may improve athletic performance and decrease the incidence of lower back injuries during dynamic, high impact physical activity by stabilising the spine [16, 22]; it is particularly important for fast bowlers who are most prone to lower back injuries and subjected to high ground reaction forces of the front foot when landing at the popping crease. Further, this is important to consider as traditional coaching techniques do not take these ground reaction forces into account when training (coaches do not measure ground reaction forces).

Repeat sprint ability (25-m shuttle distance) improved significantly $(p<0.05)$ throughout the intervention period in both the control and experimental groups, meaning that there was an improvement in cardiovascular fitness and/or muscle elastic return capacity. The fact that both groups progressed shows that traditional practices do focus on the core needs of the game, such as sprinting between the wickets; however, the benefits to the players may be greater if they are exposed to a strength and conditioning program, as well as traditional training. Additionally, the nature of the sprint activity of bowlers, batsmen, and fielders means that it is important that coaches are aware of the acute and chronic neuromuscular responses as a result of the constant accelerations and decelerations [21]. Thus, there is a need to implement repeat sprint ability training (such as 25-m shuttles) to focus on eccentric loading of the lower limbs and thus avoid injuries. Furthermore, studies on batsmen have shown a decrease in eccentric peak torque of the knee flexors and extensors when running between the wickets (during high intensity running in a 7-over period), potentially increasing the risk of hamstring strains [2], thus further proving the importance of eccentric work through repeat sprint training.

Flexibility increased significantly $(p<0.05)$ in the experimental group. This improvement was most likely due to the dynamic warm-up that was performed prior to and the static stretching completed after the workouts. There is, however, conflicting evidence in terms of the relationship between increased flexibility and reduced risk of injury [23]. Some studies have shown that and increased flexibility may in fact increase the risk of injury, but may be beneficial for sports that require a greater range of motion $[24,25]$. Research has shown, though, that flexibility imbalances in athletes may be the main cause for injuries in specific sports [26].

\section{Limitations}

There are a number of limitations acknowledged by the authors with reference to the present study. Firstly, the fact that 2 additional sessions per week were performed by the experimental group (and not the control group) may be perceived as a limitation to the study; however, as these sessions only required additional 90 minutes per week (extra 37.5\% compared with the control group) and benefited the players' physical fitness (in the experimental group), the intervention program turned out worthwhile. This is further justified if one considers that no additional exercises or gym work was carried out by either group during the intervention period. The intervention was also to expand the understanding of schoolboy strength and conditioning, which is currently lacking.

Secondly, it may be seen as a limitation that the intervention period was as short as 4 weeks. This is, however, the longest period that private schools in South Africa can utilise for pre-season cricket training. Furthermore, the research results have shown that this is a sufficient amount of time for specific adaptations to occur.

Lastly, no performance or injury data were collected for the current study. Further research should gather these data to determine whether the intervention program has an impact on a player's performance, as well as the risk of injury or re-occurrence of a previous injury.

\section{Conclusions}

The findings of this investigation indicate that the CricFit intervention may be used by coaches and conditioning specialists to improve general fitness throughout the pre-season period. While traditional coaching techniques did increase some measures, implementing 2 additional conditioning sessions per week was shown to be beneficial to the players. Further research should assess whether the program can be used to prevent injuries in players through the tracking of injury data. This is particularly important for adolescent players who are the most prone. Physical education teachers 
may also utilise the intervention to improve the general fitness of individuals in a school environment.

The program can also be implemented at any location without any specialised equipment. This is especially important for schools, teams, and clubs that do not have access to particular equipment or facilities. Lastly, the intervention is not time-consuming as it only lasts 35-45 minutes per session (including the warm-up and cool-down), twice a week for 4 weeks. This is essential for adherence to the program and remains important in a school environment where pupils have to focus on other aspects such as academic and cultural commitments.

\section{Acknowledgements}

The work is based on research supported by the National Research Foundation (NRF) of South Africa. Any opinions, findings, conclusions, or recommendations expressed in this material are those of the authors and therefore the NRF do not accept any liability in regard thereto.

\section{Disclosure statement}

No author has any financial interest or received any financial benefit from this research.

\section{Conflict of interest}

The authors state no conflict of interest.

\section{References}

1. Mukandi I, Turner AN, Scott P, Johnstone JA. Strength and conditioning for cricket fast bowlers. Strength Cond J. 2014;36(6):96-106; doi: 10.1519/SSC.0000000000 000099.

2. Pote L, Christie CJ. Physiological responses of batsmen during a simulated One Day International century. SA J Sports Med. 2016;28(2):39-42; doi: 10.17159/2078516x/2016/v28i2a163.

3. Noakes TD, Durandt JJ. Physiological requirements of cricket. J Sports Sci. 2000;18(12):919-929; doi: 10.1080/ 026404100446739.

4. Milsom NM, Barnard JG, Stretch RA. Seasonal incidence and nature of cricket injuries among elite South African schoolboy cricketers. SA J Sports Med. 2007; 19(3):80-84; doi: 10.17159/2078-516X/2007/v19i3a259.

5. Stretch RA, Trella C. A 3 year investigation into the incidence and nature of cricket injuries in elite South African schoolboy cricketers. SA J Sports Med. 2012;24(1): 10-14; doi: 10.17159/2078-516X/2012/v24i1a360.

6. Pote L, Christie CJ. Strength and conditioning practices of university and high school level cricket coaches: aSouth African context. J Strength Cond Res. 2016;30(12): 3464-3470; doi: 10.1519/JSC.0000000000001432.

7. Stretch RA. Junior cricketers are not a smaller version of adult cricketers: a 5-year investigation of injuries in elite junior cricketers. SA J Sports Med. 2014;26(4):1 23-127; doi: 10.7196/SAJSM.543.

8. Stretch RA. Incidence and nature of epidemiological injuries to elite South African cricket players. S Afr Med J. 2001;91(4):336-339.

9. Dennis R, Farhart P, Goumas C, Orchard J. Bowling workload and the risk of injury in elite cricket fast bowlers. J Sci Med Sport. 2003;6(3):359-367; doi: 10.1016/ S1440-2440(03)80031-2.

10. Cronin JB, Sharp AP, Stronach B, Deuchrass R, Bressel E, Shackel DF, et al. Strength and conditioning for throwing in cricket. Strength Cond J. 2016;38(6):1-9; doi: 10.1519/SSC.0000000000000254.

11. Faigenbaum AD, Kraemer WJ, Blimkie CJ, Jeffreys I, Micheli LJ, Nitka M, et al. Youth resistance training: updated position statement paper from the National Strength and Conditioning Association. J Strength Cond Res. 2009;23(5 Suppl):S60-S79; doi: 10.1519/JSC.0b 013e31819df407.

12. Sanctuary C. Elite cricket - intelligent training for young bowling success. Peak Performance. 2014;253:8-11.

13. Finch CF, Elliot BC, McGrath AC. Measures to prevent cricket injuries: an overview. Sports Med. 1999;28(4): 263-272; doi: 10.2165/00007256-199928040-00004.

14. Mjølsnes R, Arnason A, Østhagen T, Raastad T, Bahr R. A 10-week randomized trial comparing eccentric vs. concentric hamstring strength training in well-trained soccer players. Scand J Med Sci Sports. 2004;14(5): 311-317; doi: 10.1046/j.1600-0838.2003.367.x.

15. Bloomfield J, Polman R, O’Donoghue P, McNaughton L. Effective speed and agility conditioning methodology for random intermittent dynamic type sports. J Strength CondRes. 2007;21(4):1093-1100; doi:10.1519/R-20015.1.

16. Woolmer B, Noakes T, Moffett H. Bob Woolmer's art and science of cricket. Cape Town: Struik Publishers; 2008.

17. Olivier B, Stewart AV, Olorunju SAS, McKinon W. Static and dynamic balance ability, lumbo-pelvic movement control and injury incidence in cricket pace bowlers. J Sci Med Sport. 2015;18(1):19-25; doi: 10.1016/j. jsams.2013.10.245.

18. Hopkins WG. How to interpret changes in an athletic performance test. Sports Sci. 2004;8:1-7.

19. Foden M, Astley S, Comfort P, McMahon JJ, Matthews MJ, Jones PA. Relationships between speed, change of direction and jump performance with cricket specific speed tests in male academy cricketers. J Trainol. 2015; 4:37-42; doi: 10.17338/trainology.4.2_37.

20. Taliep MS, Prim SK, Gray J. Upper body muscle strength and batting performance in cricket batsmen. J Strength Cond Res. 2010;24(12):3484-3487; doi: 10.1519/JSC. 0b013e3181e7261b.

21. Subramanian A. Investigation of core strength training induced adaptations on selected physical and physiological parameters of cricket players. Int J Phys Educ Fitness Sports. 2014;3(1):65-70; doi: 10.26524/14111. 
22. Allen BA, Hannon JC, Burns RD, Williams SM. Effect of a core conditioning intervention on tests of trunk muscular endurance in school-aged children. J Strength Cond Res. 2014;28(7):2063-2070; doi: 10.1519/JSC. 0000000000000352.

23. Thacker SB, Gilchrist J, Stroup DF, Kimsey CD Jr. The impact of stretching on sports injury risk: a systematic review of the literature. Med Sci Sports Exerc. 2004;36(3): 371-378; doi: 10.1249/01.MSS.0000117134.83018.F7.

24. Knapik JJ, Jones BH, Bauman CL, Harris JM. Strength, flexibility and athletic injuries. Sports Med. 1992;14(5): 277-288.

25. Kokkonen J, Nelson AG, Cornwell A. Acute muscle stretching inhibits maximal strength performance. Res Q Exerc Sport. 1998;69(4):411-415; doi: 10.1080/02701367. 1998.10607716.

26. Knapik JJ, Bauman CL, Jones BH, Harris JM, Vaughan L. Preseason strength and flexibility imbalances associated with athletic injuries in female collegiate athletes. Am J Sports Med. 1991;19(1):76-81; doi: 10.1177/03 6354659101900113. 